\title{
Impact on Quality of Life of Patients Treated by Different File Systems for Root Canal Treatment
}

Priyanka L.S. ${ }^{1} \quad$ Lakshmi Nidhi Rao $^{1} \quad$ Aditya Shetty $^{1} \quad$ Mithra N. Hegde ${ }^{1} \quad$ Chitharanjan Shetty $^{1}$

\begin{abstract}
Address for correspondence Lakshmi Nidhi Rao, MDS, Department of Conservative Dentistry and Endodontics, A.B. Shetty Memorial Institute of Dental Sciences, Mangalore, Karnataka, India (e-mail: dimpirao@rediffmail.com).
\end{abstract}

\begin{abstract}
Keywords

- quality of life

- file systems

- postoperative pain
\end{abstract}

\section{Introduction}

World Health Organization's (WHO) definition of health is "a complete state of physical, mental, and social well-being and not just the absence of disease."1 As a multidimensional structure, health service studies have focused on health.
The theory of health status follows the bio-psycho-social health paradigm that integrates symptoms, physical activity, and emotional and social well-being. ${ }^{2}$ The outcomes for these types of oral health problems and therapy are defined by the term "oral health-related quality of life" (OHRQoL). This definition applies to the degree to which oral diseases published online

January 7, 2020
DOI https://doi.org/

10.1055/s-0040-1722108 ISSN 2582-4287. (c) 2020. Nitte (Deemed to be University).

This is an open access article published by Thieme under the terms of the Creative Commons Attribution-NonDerivative-NonCommercial-License, permitting copying and reproduction so long as the original work is given appropriate credit. Contents may not be used for commercial purposes, or adapted, remixed, transformed or built upon. (https://creativecommons.org/licenses/by-nc-nd/4.0/).

Thieme Medical and Scientific Publishers Pvt. Ltd. A-12, 2nd Floor, Sector 2, Noida-201301 UP, India 
influence the normal functioning of individuals and is considered an integral part of overall health and well-being. ${ }^{3}$ The WHO acknowledges the OHRQoL as an integral part of the Global Oral Health Program. This is a multidimensional concept dealing with OHRQoL). ${ }^{4,5}$ The Oral Health Impact Profile (OHIP) is considered to be the most detailed evaluation of the quality of life associated with oral health. ${ }^{5}$ They have been commonly used in numerous populations research studies. ${ }^{6}$ The purpose of this index is to provide a quantitative measure of self-reported dysfunction discomfort and disability resulting from oral conditions to quantify seven dimensions of impacts of oral conditions on OHRQoL including functional limitation, physical pain, psychological discomfort, physical disability, psychological disability, social disability, and handicap. ${ }^{7}$

During the preparation of the root canal, instrumentation may cause the extrusion of debris, microorganisms, and irrigating solution via apical foramen, resulting in an exacerbated inflammatory response and therefore pain. ${ }^{8}$ Studies comparing a few of these rotary systems (Protaper gold and Hyflex) measured pain over periods of 24 hours to 1 week. Pain has always been present in all studies and has been more serious in the 24 hours following the use of instruments. ${ }^{8-12}$

Interrupting the endodontic pain and restoring dental function is not sufficient for root canal therapy to be approved, as postoperative pain may impede future intervention. ${ }^{3}$ Therefore, clinicians need to be aware of the impact felt by patients postoperatively so that they can take precautions.

The study aims to compare the impact of various root canal preparation systems on patients' quality of life and correlate postoperative pain with the impact on the quality of life.

\section{Materials and Methods}

This study received approval from the institutional ethics committee (ABSM/EC 18/2019 dated on 28/06/2019). All participants signed an informed consent declaration.

The inclusion criteria were those patients indicated for root canal treatment without preoperative pain, that is, asymptomatic irreversible pulpitis, chronic hyperplastic pulpitis, asymptomatic apical periodontitis, and anterior teeth (maxillary and mandibular). The exclusion criteria were pregnancy, systemic disease with contraindication for root canal treatment (recent myocardial infarction, uncontrolled hypertension, and uncontrolled diabetes), ${ }^{14}$ pulp and periapical involvement with spontaneous pain, symptomatic irreversible pulpitis, and posterior teeth.

The diagnosis was based on the examination of the main complaint, the medical and dental history, the radiographic investigation, and the pulp test using cotton and icing spray (Endo-Frost, Coltene Whaledent, Langenau, Germany).

The survey was done for patients requiring root canal treatment, that is, patients were randomly allotted for different file systems using table of random numbers.

\section{Statistical Analysis}

A sample calculation was performed to compare treatment methods that affect patients' quality of life. Assuming a confidence level of $95 \%$, a power of $80 \%$, a standard deviation of 2.0 , and a minimum difference to be detected between groups of 1.5 points of mean impact for the overall OHIP-14 score, a minimum of 30 patients for each group totaling 90 patients is calculated.

\section{Data Collection}

Randomization of the treatments with Protaper Gold (Dentsply, Tulsa Dental Specialties, Tulsa, Oklahoma, United States), Neoendo flex (Neoendo, India), Hyflex EDM/CM (Coltene Whaledent) was determined. A questionnaire was given to each patient before treatment to address demographic and clinical characteristics. The patient was given a form with a visual analog scale (VAS) and the OHIP-14 questionnaire (-Supplementary Material, available in the online version) in the first 24 hours after the root canal preparation with the different instrument systems.

The VAS had a $10-\mathrm{cm}$ line printed at one end with 0 (without pain) and the other end with 10 (the worst possible pain). After using the root canal preparation system, the patient was instructed to place a mark on the line corresponding to the sensation of pain intensity. The OHIP-14 questionnaire has been used to calculate the impact on the quality of life of root canal preparation. This questionnaire has been validated by an institutional ethical committee and has seven domains (functional limitation, physical pain, psychological discomfort, physical disability, psychological disability, social disability, and handicap), each of which has two criteria. After root canal preparation, the impact rate was measured in the first 24 hours and graded using a Likert scale: never $=0$; sometimes $=1$; often $=2$; sometimes $=3$; and very often $=4$. The number is calculated from the sum of the element scores, ranging from 0 to 56 points, with higher scores suggesting a worse OHRQoL.

The primary outcome was the root canal preparation's postoperative impact. The secondary result was the severity of pain. Based on statistical analysis, both results were evaluated quantitatively.

The Kruskal-Wallis test was used to compare the mean total OHIP-14 group and pain score (VAS) among study groups ( $p<0.05$ was considered statistically significant). In which the values are statistically significant, Mann-Whitney U test was performed. Spearman's correlation coefficients $\left(r_{s}\right)$ were used to find the correlation between pain and OHIP in each study group.

\section{Results}

One hundred and twenty patients were screened, 30 of whom were excluded for not meeting the eligibility criteria.

- Table 1 shows the impact values of root canal preparation for each group on the OHIP-14 for the whole sample. The most frequently found impacts were "felt self-consciousness." 


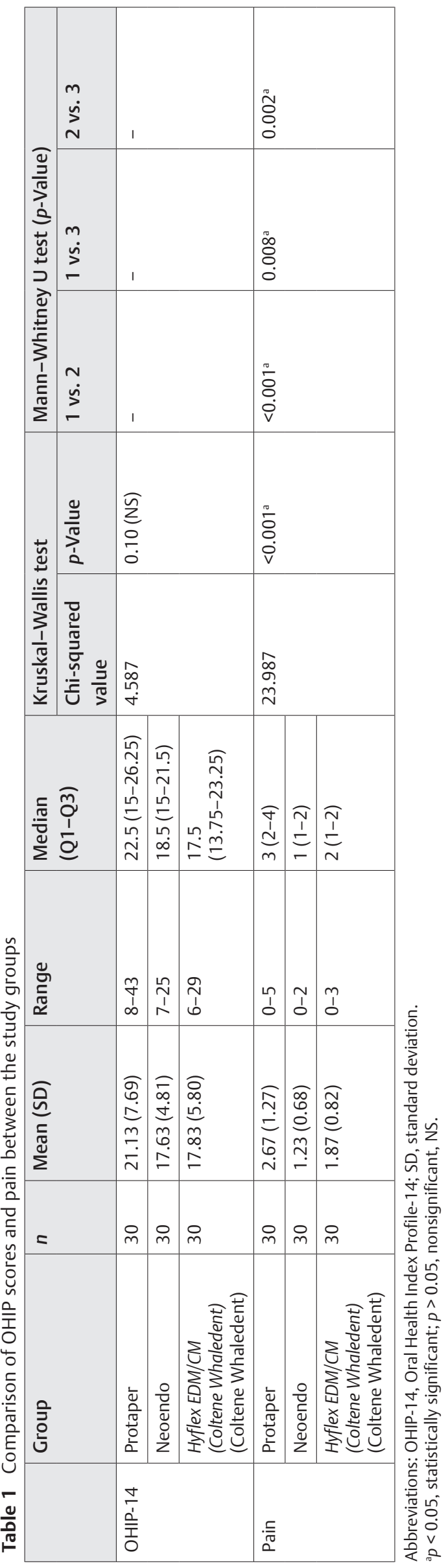

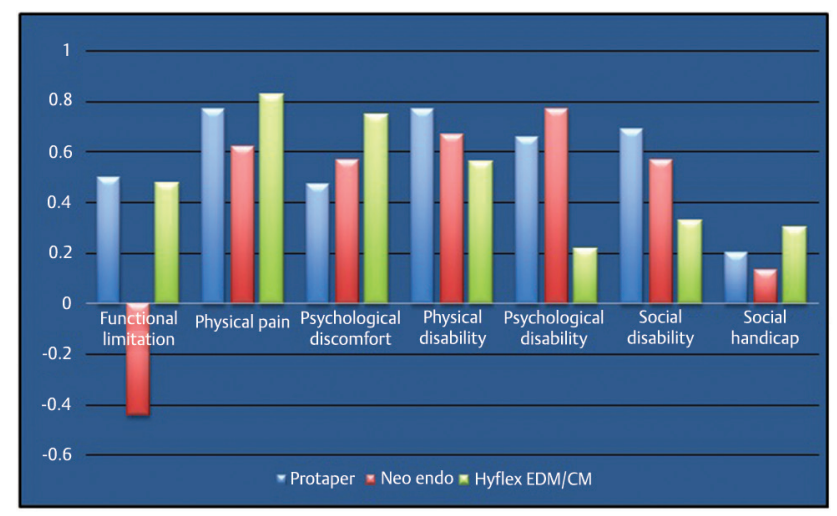

Fig. 1 Spearman's correlation test. $p<0.05$, statistically significant; $p>0.05$, nonsignificant, NS.

No significant differences between groups were identified with regard to the severity of the impact following root canal preparation. The mean VAS score (Protaper Gold [Dentsply, Tulsa Dental Specialties, Tulsa, Oklahoma, United States)-2.67, Neoendo flex (Neoendo, India)-1.23, Hyflex $\mathrm{EDM} / \mathrm{CM}$ [Coltene Whaledent]-1.87) was significantly different with the $p$-value $<0.001$.

- Fig. 1 shows there is a positive correlation found with OHIP and VAS except for "functional limitation" in Neoendo.

\section{Discussion}

The patient's perspective on his/her health status is important for the determination of treatment planning as well as for the assessment of health-related outcomes. ${ }^{15}$ Pain is undeniably the major determinant of quality of life and is often the main reason that people seek root canal treatment. ${ }^{16}$ Postoperative pain is due to individual patient-related factors, idiopathic causes, and aspects based on chemical-mechanical debridement of root canals. ${ }^{17}$ Debris resulting from the use of dental instruments can be extruded to periodontal tissues, ${ }^{8,18,19}$ and the volume of extruded debris depends on the technique of instrumentation used. ${ }^{20-22}$ Therefore, the intensity of postoperative pain may be associated with the root canal preparation system. ${ }^{11}$

Also, patients with an indication for root canal treatment, without preoperative pain, were included in the ongoing randomized clinical trial. In an attempt to isolate possible predictors of postoperative pain, teeth with a history of pulp and periapical involvement with spontaneous pain are removed. Patients with a diagnosis of symptomatic irreversible pulpitis were excluded.

The 24-hour follow-up period for determining the key outcome (impact of the instrumentation on quality of life) was calculated because postoperative pain that usually occurs as a result of the acute inflammatory response in the periapical tissues starts within a few hours or days of instrumentation of the root canal. ${ }^{10}$ The inflammatory response of the periodontal ligament is more dependent on the design of the endodontic instrument than the number of instruments inserted into the root canal, according to clinical studies testing the rotary file systems. ${ }^{23}$ 
Tanalp et $\mathrm{al}^{24}$ performed a quantitative analysis of the amount of apically extruded debris using three different rotary instrumentation systems, finding that all rotary instrumentation techniques produce some apical debris extrusion. In the present study, the impact of the postoperative period worsened with the domains "physical pain," "psychological discomfort." No significant differences were found in the comparison of OHIP scores between study groups. The immunological aspects of postoperative flare-up have been studied by several researchers who concluded that antigens emanating from the root canal result in the development of an antigenantibody complex when pushed beyond the apical foramen, which can lead to a significant inflammatory response. ${ }^{25-28}$

The significant impact rate provided by the "felt self-conscious" element was verified by the significant positive association with the pain assessed using the VAS. Research assessing the relationship between endodontic factors and OHRQoL also found higher scores in the domains of physical pain and psychological discomfort indicating that the consequences of endodontic problems are conveyed hierarchically by symptoms and harm ${ }^{29}$

In addition to performing root canal preparation with sufficient disinfection and pain control, the dentist must provide treatment capable of preventing or treating the negative effects of such therapy. A holistic approach leads to increased commitment to postoperative care, which undoubtedly has an impact on the quality of life.

\section{Conclusion}

Within the limitations of the present study, Protaper Gold (Dentsply, Tulsa Dental Specialties, Tulsa, Oklahoma, United States) showed a highly significant difference in postoperative pain when compared with other file systems. No significant differences were found in the quality of life among the study groups.

\section{Note}

This study provides a clinical guideline for the dentists for successful endodontic therapy without postoperative pain.

\section{Conflict of Interest}

None declared.

\section{References}

1 WHO. World Health Organization Constitution. Geneva, Switzerland: World Health Organization. 1948. Available from http://www.who.int/governance/eb/who_constitution en.pdf. Accessed January 19, 2020

2 Kleinman A, The Illness Narratives: Suffering, Healing, and the Human Condition; 1988 New York: Basic Books

3 Sischo L, Broder HL. Oral health-related quality of life: what, why, how, and future implications. J Dent Res 2011;90(11): 1264-1270

4 Allen PF. Assessment of oral health related quality of life. Health Qual Life Outcomes 2003;1:40
5 Locker D, Allen F. What do measures of 'oral health-related quality of life' measure? Community Dent Oral Epidemiol 2007; 35(6):401-411

6 Locker D, Gibson B. The concept of positive health: a review and commentary on its application in oral health research. Community Dent Oral Epidemiol 2006;34(3):161-173

7 Slade GD, Spencer AJ. Development and evaluation of the Oral Health Impact Profile. Community Dent Health 1994; 11(1):3-11

8 Relvas JBF, Bastos MM, Marques AA. Garrido ADB, Sponchiado EC Jr. Assessment of postoperative pain after reciprocating or rotary NiTi instrumentation of root canals: a randomized, controlled clinical trial. Clin Oral Investig 2016;20(8):1987-1993

9 Kherlakian D, Cunha RS, Ehrhardt IC. Zuolo ML, Kishen A, da Silveira Bueno CE. Comparison of the incidence of postoperative pain after using 2 reciprocating systems and a continuous rotary system: a prospective randomized clinical trial. J Endod 2016;42(2):171-176

10 Neelakantan P, Sharma S. Pain after single-visit root canal treatment with two single-file systems based on different kinematics-a prospective randomized multicenter clinical study. Clin Oral Investig 2015;19(9):2211-2217

11 Nekoofar MH, Sheykhrezae MS, Meraji N, et al. Comparison of the effect of root canal preparation by using WaveOne and ProTaper on postoperative pain: a randomized clinical trial. J Endod 2015;41(5):575-578

12 Oliveira PS, da Costa KNB, Carvalho CN, Ferreira MC. Impact of root canal preparation performed by ProTaper Next or Reciproc on the quality of life of patients: a randomized clinical trial. Int Endod J 2019;52(2):139-148

13 Ng Y-L, Glennon JP, Setchell DJ, Gulabivala K. Prevalence of and factors affecting post-obturation pain in patients undergoing root canal treatment. Int Endod J 2004;37(6):381-391

14 American Association of Endodontists. 2017. Available at: https://www.aae.org/specialty/wpcontent/uploads/ sites/2/2017/09/endo-competency-whitepaper.pdf. Accessed November 30, 2020

15 Locker D. Oral health and quality of life. Oral Health Prev Dent 2004;2(Suppl 1):247-253

16 Iqbal MK, Kratchman SI, Guess GM, Karabucak B, Kim S. Microscopic periradicular surgery: perioperative predictors for postoperative clinical outcomes and quality of life assessment. J Endod 2007;33(3):239-244

17 Siqueira JF Jr, Rôças IN, Favieri A, et al. Incidence of postoperative pain after intracanal procedures based on an antimicrobial strategy. J Endod 2002;28(6):457-460

18 Kuştarci A, Akpinar KE, Er K. Apical extrusion of intracanal debris and irrigant following use of various instrumentation techniques. Oral Surg Oral Med Oral Pathol Oral Radiol Endod 2008;105(2):257-262

19 Logani A, Shah N. Apically extruded debris with three contemporary $\mathrm{Ni}-\mathrm{Ti}$ instrumentation systems: an ex vivo comparative study. Indian J Dent Res 2008;19(3):182-185

20 Bürklein S, Schäfer E. Apically extruded debris with reciprocating single-file and full-sequence rotary instrumentation systems. J Endod 2012;38(6):850-852

21 Ferraz CC, Gomes NV, Gomes BP, Zaia AA, Teixeira FB, Souza-Filho FJ. Apical extrusion of debris and irrigants using two hand and three engine-driven instrumentation techniques. Int Endod J 2001;34(5):354-358

22 Nair PN, Henry S, Cano V, Vera J. Microbial status of apical root canal system of human mandibular first molars with primary apical periodontitis after "one-visit" endodontic treatment. Oral Surg Oral Med Oral Pathol Oral Radiol Endod 2005; 99(2):231-252 
23 Caviedes-Bucheli J, Azuero-Holguin MM, Gutierrez-Sanchez L, et al. The effect of three different rotary instrumentation systems on substance $P$ and calcitonin gene-related peptide expression in human periodontal ligament. J Endod 2010;36(12): 1938-1942

24 Tanalp J, Kaptan F, Sert S, Kayahan B, Bayirl G. Quantitative evaluation of the amount of apically extruded debris using 3 different rotary instrumentation systems. Oral Surg Oral Med Oral Pathol Oral Radiol Endodontol 2006;101(2):250-257

25 Al-Omari MAO, Dummer PMH. Canal blockage and debris extrusion with eight preparation techniques. J Endod 1995; 21(3):154-158
26 Naidorf IJ. Endodontic flare-ups: bacteriological and immunological mechanisms. J Endod 1985;11(11):462-464

27 Perrini N, Fonzi L. Mast cells in human periapical lesions: ultrastructural aspects and their possible physiopathological implications. J Endod 1985;11(5):197-202

28 Torabinejad M, Eby WC, Naidorf IJ. Inflammatory and immunological aspects of the pathogenesis of human periapical lesions. J Endod 1985;11(11):479-488

29 Liu P, McGrath C, Cheung G. What are the key endodontic factors associated with oral health-related quality of life? Int Endod J 2014;47(3):238-245 